\section{Military Technical College Kobry El-Kobbah, Cairo, Egypt}

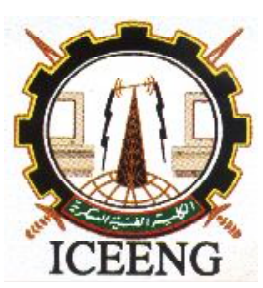

\title{
Chemically Reduced Graphene Oxide as Electrodes for Energy Storage Applications
}

\author{
By \\ Mazhar B. Tayel ${ }^{1}$, Moataz M. Soliman ${ }^{2}$, Shaker Ebrahim ${ }^{2}$, Mohamed E. Harb ${ }^{1, *}$
}

\section{Abstract:}

Supercapacitors have attracted increasing attention due to their widespread applications, such as hybrid electric vehicles, power tools, portable electronic equipment and other devices. Using larger surface area of graphene electrodes and thinner dielectrics to achieve larger capacitances is a new trend for increasing capacitance of supercapacitors. This allows for energy densities greater than those of conventional capacitors and power densities greater than those of batteries.. In this paper, graphene oxide was synthesized by improved Hummers method. polyaniline PANI/grapheneoxide (GO) nanocomposite electrode materials were prepared from aniline (ANI), GO and ammoniumpersulfate (APS) by insitu chemical polymerization in ice bath. GO in composite was reduced for $5 \mathrm{~h}$ and $20 \mathrm{~h}$. The crystal structure and the surface topography of all materials were characterized by Fourier transform infrared spectroscopy (FTIR) and Raman spectroscopy. The electrochemical properties were evaluated by cyclic voltammetry $(\mathrm{CV})$, charge-discharge measurements, electrical impedance spectroscopy (EIS) and a four-point probe, respectively. The results show that with increasing reduction time, the oxygen content on the surface of GO was decreased, leading to increased ID/IG ratio in the Raman spectra of GO and increased conductivity of composite. Consequently, the capacitance properties of RGO/PANI composites could be significantly improved by the reduction of GO for $20 \mathrm{~h}$. The GO /PANI composite reduced for $20 \mathrm{~h}$ had a specific capacitance as high as $1405.68 \mathrm{~F} / \mathrm{g}$ at scan rate of $1 \mathrm{mV} / \mathrm{s}$ compared with $291.73 \mathrm{~F} / \mathrm{g}$ for pristine graphene film.

Keywords:

Graphene oxide, Graphene; Polyaniline, Hybrid supercapacitor and Composite.

${ }^{1}$ Department of Electrical Engineering, Faculty of Engineering, Alexandria University

${ }^{2}$ Department of Materials Science, Institute of Graduate Studies and Research, Alexandria University. 


\section{Introduction:}

Supercapacitors represent an attractive alternative for portable electronics and automotive applications due to their high specific power and extended life. In fact, the growing demand of portable systems and hybrid electric vehicles, memory protection in CMOS, logic circuit, VCRs, CD players, PCs, UPS in security alarm systems, remote sensing, smoke detectors, etc. require high power in short-term pulses[1, 2]. So, in the last 20 years, electrochemical capacitors have been required for the development of large and small devices driven by electrical power [3].

Hybrid capacitors attempt to exploit the relative advantages and mitigate the relative disadvantages of EDLCs and pseudocapacitors to realize better performance characteristics. Utilizing both Faradaic and non-Faradaic processes to store charge, hybrid capacitors have achieved energy and power densities greater than EDLCs without the sacrifices in cycling stability and affordability that have limited the success of pseudocapacitors. Such limitations may be overcome by combining PANI with carbon materials [4-6], because the combination improves the electrochemical performances of PANI, such as conductivity, specific capacitance, and cyclic stability.

In this work, GO/aniline composite was synthesized by an in situ polymerization. Sodium hydroxide is used for reduction of graphene oxide for different time. Supercapacitor electrochemical performance was assessed using cyclic voltammetry (CV), electrical impedance spectroscopy (EIS), and galvanostatic charge/discharge measurements.

\section{EXPERIMENTAL WORK}

\subsection{Materials}

Graphite powder was purchased from Fischer Scientific. Sulphuric acid (98 wt.\%), nitric acid (70 wt.\%), potassium permanganate and sodium nitrite were purchased from Sigma-Aldrich Ltd. Barium chloride (99\%) was purchased from ALEC. Potassium hydroxide, silver chloride, sodium hydroxide and hydrogen peroxide (30 wt.\%) were obtained from local chemical companies. Aniline (99\%) was purchased from $\mathrm{CDH}$. Ammonium persulphate $(98.5 \%)$ was purchased from WINLAB. Hydrochloric acid (37\%) and camphor sulfonic acid were obtained from Mereck.

\subsection{Reduced GO/PANI Composite Preparation}

Graphene oxide was prepared by modified Hummers method [7-10]. Graphene/polyaniline composite was prepared. Weight of $0.4 \mathrm{mg} \mathrm{mL}^{-1} \mathrm{GO}$ (20\% weight) in $180 \mathrm{~mL}$ distilled water was ultrasonicated for $1 \mathrm{~h}$ to obtain a yellow brown 
suspension. Aniline of $1.6 \mathrm{mg}(0.1171 \mathrm{M})$ was slowly added into the suspension and a stable GO/aniline suspension was obtained after stirring violently. A mixture of concentrated hydrochloric acid, ammonium persulphate (APS) in $20 \mathrm{~mL}$ distilled water was then slowly added to the suspension with stirring. The molar ratio of aniline, hydrochloric acid and APS was 1:1:1. The reaction was conducted by the insitu polymerization method in ice bath for $1 \mathrm{~h}$ and the yellow-brown suspension gradually changed to deep green color. The prepared composite was filtered, rinsed with distilled water. Then, the GO was reduced and the PANI was dedoped by $14.4 \mathrm{~mL} 8 \mathrm{M}$ sodium hydroxide at $95{ }^{\circ} \mathrm{C}$ for $5 \mathrm{~h}$ and $20 \mathrm{~h}$. In the basic medium, the color was changed from deep green to dark purple. The composite was filtered and rinsed with distilled water until the filtrate became neutral. Thirdly, the product was mixed with campher sulfonic acid (ratio 1:3) and stirred for $24 \mathrm{~h}$ for PANI redoping. The graphene/PANI composite of different reduction time of GO are shown in Table 1 with their abbreviated name.

Table (1): Graphene/PANI composites

\begin{tabular}{|l|c|c|c|}
\hline No & $\begin{array}{c}\text { Reduction } \\
\text { time (hours) }\end{array}$ & $\begin{array}{c}\text { Graphene/PANI } \\
\text { composite } \\
\text { undoped } \\
\text { (After GO } \\
\text { reduction) }\end{array}$ & $\begin{array}{c}\text { Graphene/PAN } \\
\text { I composite } \\
\text { (doped with } \\
\text { CSA) }\end{array}$ \\
\hline 1 & 5 & GP5 & GPD5 \\
\hline 2 & 20 & GP20 & GPD20 \\
\hline
\end{tabular}

\subsection{Fabrication of the Introduced Supercapacitor}

Graphene/PANI composites were deposited on the Stainless steel 304 current collector The separator was a filter paper soaked in aqueous potassium hydroxide (6 M). Supercapacitor was assembled by stacking two fabricated electrodes with a separator. The fabricated supercapacitor was sealed by laminating it with plastic foil and fixing the layers together by two clamps. Figure (1) shows the structure of supercapacitor.

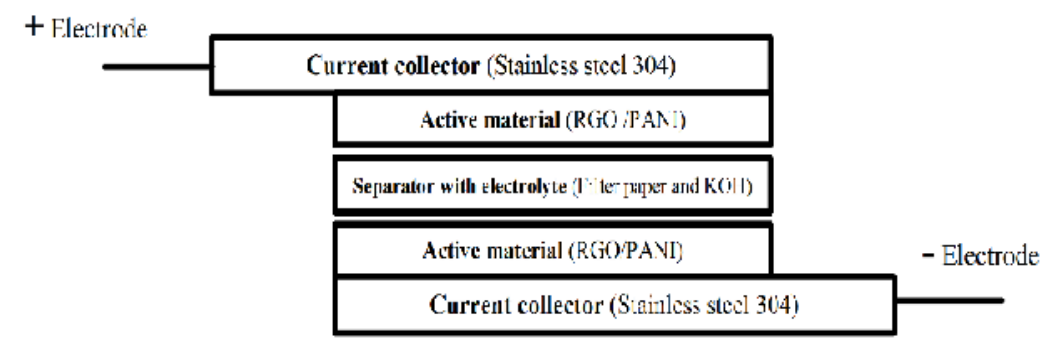

Figure (1): Fabricated supercapacitor structure 


\subsection{Electrochemical Measurements}

The electrochemical performance was analyzed for supercapacitor electrodes in a two-electrode system by CV and EIS using Potentiostat Gamry G750 instrument and the galvanostatic charge-discharge characteristic performance was carried out with a Gamry 3000. The $\mathrm{CV}$ response of the electrodes was measured at different scan rates varying from $1 \mathrm{mV} / \mathrm{s}$ to $100 \mathrm{mV} / \mathrm{s}$. EIS measurements were carried out without dc bias with sinusoidal signal of $5 \mathrm{~mA}$ over the frequency range from $0.05 \mathrm{~Hz}$ to $1 \mathrm{MHz}$. A four-point probe was used for measuring the sheet resistance by passing a current through the two outer probes and measuring the voltage through the inner probes.

\section{RESULTS AND DISCUSSION}

The FTIR spectra of GO, PANI and the chemically synthesized GP1 and GP2 are shown in Figure (2). PANI shows vibration bands at 3417, 2372, 1588, 1495, 1322, 1164 and $848 \mathrm{~cm}^{-1}$. The peaks at 3418 and $2372 \mathrm{~cm}^{-1}$ are attributed to $\mathrm{NH}_{2}^{+}$and $\mathrm{N}-\mathrm{H}$ stretching modes, The peaks at 1588 and $1495 \mathrm{~cm}^{-1}$ are attributed to $\mathrm{C}=\mathrm{N}$ and $\mathrm{C}=\mathrm{C}$ stretching modes for the quinoid and benzenoid rings. The peak at about $1322 \mathrm{~cm}^{-1}$ is attributed to $\mathrm{C}-\mathrm{N}$ stretching mode for benzenoid ring. The vibration band at $1164 \mathrm{~cm}^{-1}$ is due to presence of C-N double bond. The vibration band at $848 \mathrm{~cm}^{-1}$ is attributed to $\mathrm{C}-\mathrm{H}$ vibration $[11,12]$. For the spectrum of $\mathrm{GO}$, vibration bands at $3418,1722,1625$, 1444,1385 and $1120 \mathrm{~cm}^{-1}$. The $3417 \mathrm{~cm}^{-1}$ vibration band has been attributed to the vibrations of the $\mathrm{O}-\mathrm{H}$ from the $-\mathrm{COOH}$ groups and/or the residual water. The band at $1722 \mathrm{~cm}^{-1}$ was assigned to $\mathrm{C}=\mathrm{O}$ vibration, and the vibration bands at 1625 was assigned to the vibration $\mathrm{C}=\mathrm{C}$. The vibration bands at 1444,1385 and $1120 \mathrm{~cm}^{-1}$ were assigned to $\mathrm{C}-\mathrm{O}$ in carboxyl $(\mathrm{C}-\mathrm{OH})$, epoxy and alkoxy groups respectively [19]. For graphene vibration bands at 3432, 1570, 1455 and $1120 \mathrm{~cm}^{-1}$ [12]. A strong band located at $3432 \mathrm{~cm}^{-1}$ to the stretching $\mathrm{O}-\mathrm{H}$ vibration. The disappearance of $\mathrm{C}=\mathrm{O}$ vibration (1722) shows the removal of - $\mathrm{COOH}$ groups by reduction. The band located at $1570 \mathrm{~cm}^{-1}$ can be attributed to $\mathrm{C}=\mathrm{C}$ vibration of graphene, confirming the recovery of the $\mathrm{sp}^{2}$ hybrid carbon skeleton. For graphene, the vibrations of epoxy (C-O) and alkoxy (C-O) are disappeared. The residual C-OH (vibrational band at 1455 and $1120 \mathrm{~cm}^{-1}$ ) groups may serve as a passage for the ions to the internal surface in the charge/discharge process and contributed to the wettability of the electrode $[12,13]$. With the increase of reduction time, the vibration at 1722 of $\mathrm{C}=\mathrm{O}$ was weakened, tending to be finally disappeared. The FTIR spectra of GP5 and GP20 showed all characterization peaks as pure PANI, however the bands are shifted to $3417,2371,1620,1503,1382,1160$ and $834 \mathrm{~cm}^{-1}$, respectively for GP5. In addition, the bands are shifted to $3470,2373,1638,1460,1386,1273,1081$ and $876 \mathrm{~cm}^{-1}$, respectively for GP20. This shift arises from $\pi-\pi$ interaction between graphene and PANI chains. We can expect that this $\pi-\pi$ conjugated interaction allows faradic 
charges to be effectively transported from the PANI to and through the graphene $[12,13]$.

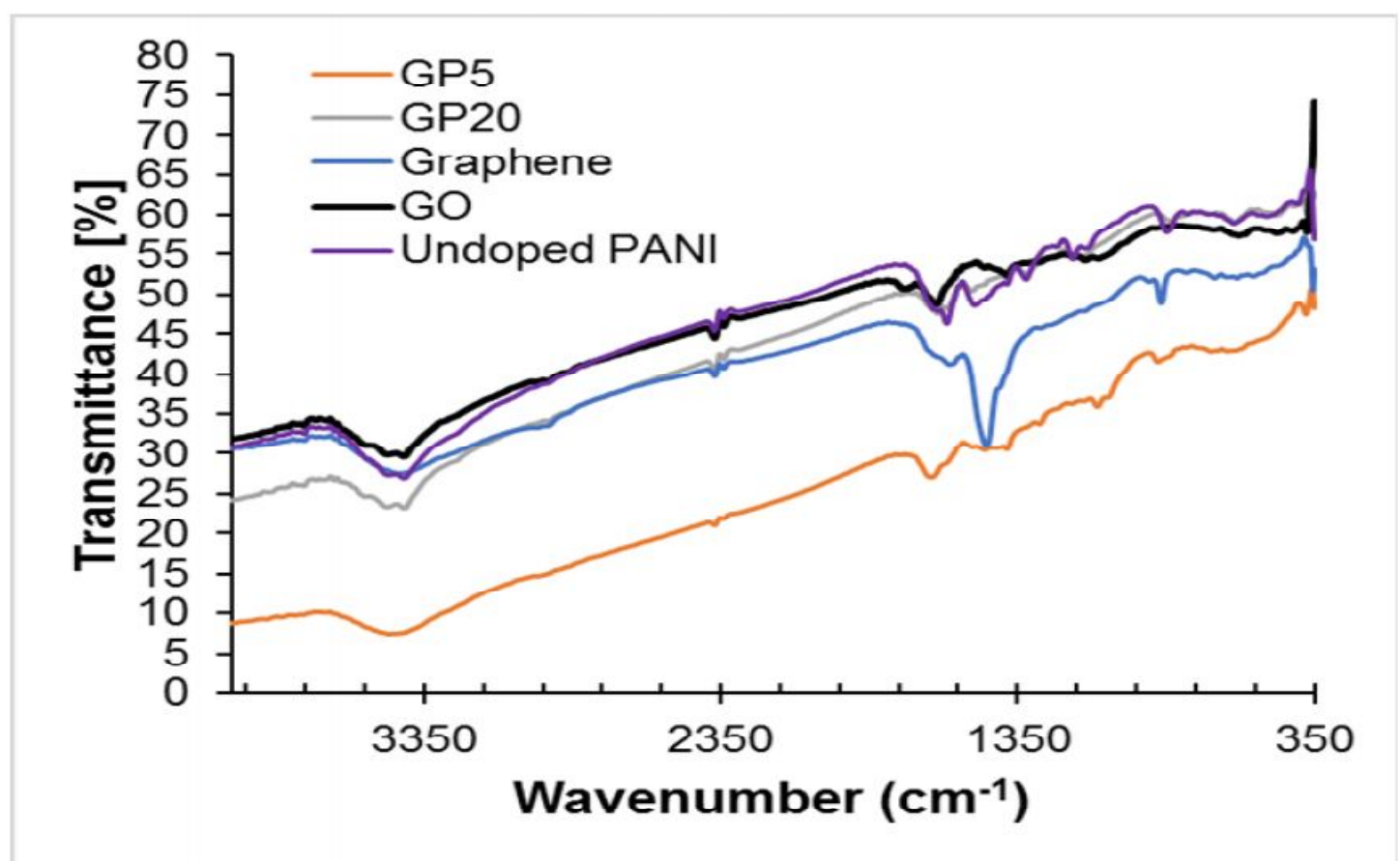

Figure (2): FTIR spectra of PANI, GO, graphene, GP5 and GP2O

Figure (3) shows the XRD patterns of undoped PANI, GO, graphene, GP1 and GP2 composite. For the PANI pattern, three characteristic peaks appear at $10.4^{\circ}, 22.2^{\circ}$ and $32.28^{\circ}$ corresponding to $(011),(020)$ and (200) amine salt crystals, respectively [14-16]. The amorphous nature of the sample is confirmed by the XRD spectrum, which shows a broad band at $22^{\circ}$ and low intense peaks related to a poorly crystallized PANI. A sharp peak in GO pattern appears at $10.5^{\circ}$, which corresponds to a (0 01) plane of GO, with an interlayer spacing of $0.84 \mathrm{~nm}$. The presence of oxygen containing groups (such as hydroxyl, epoxy and carboxyl) results in GO sheets more loosely stacked, and is attributed to the increase of the interlayer spacing. The graphene pattern shows peaks at $32.46^{\circ}, 33.66^{\circ}$ and $38.03^{\circ}$, respectively. The peak at $32.46^{\circ}$ corresponds to single or a few layers of graphene sheet with the formation of a new lattice structure. Peaks at $33.66^{\circ}$ and $38.03^{\circ}$ indicate that the van der Waals force causes aggregate or stacking of the graphene due to oxygen removal with lower hydrophilicity. XRD pattern of GP5 composite show peaks at $22.4^{\circ}, 23.84^{\circ}, 24.7^{\circ}, 30.88^{\circ}$ and $39.84^{\circ}$. The XRD pattern of GP20 composite show peaks at $21.52^{\circ}, 23.36^{\circ}, 32.62^{\circ}, 34.08^{\circ}$ and $37.12^{\circ}$. The existing peaks around $32^{\circ}, 34^{\circ}$ and $37^{\circ}$ are due to the presence of graphene in the composite, 
which indicate that the graphene has a strong interaction with the benzene ring of PANI and peak at $29^{\circ}$ is due to PANI [11, 17]. GP20 composite shows high intensity graphene peaks while GP5 composite shows low intensity graphene peaks due to low reduction time.

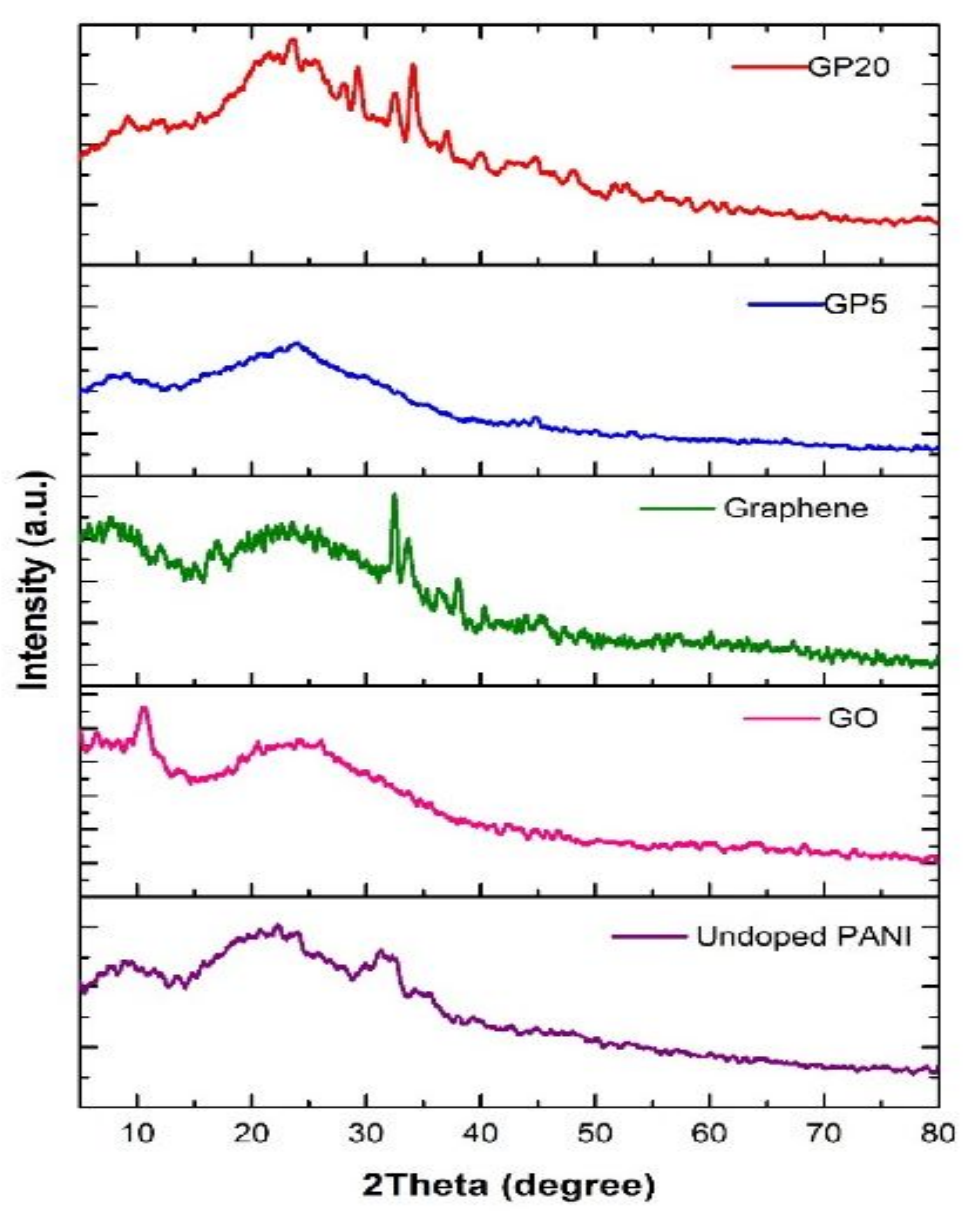

Figure (3): XRD spectra of undoped PANI, GO, graphene, GP5 and GP2O

Figure (4) shows the sheet resistance curves of GPD5 and GPD20 composites which deposited on a glass substrate. A four-point probe was used by passing a current through the two outer probes and measuring the voltage through the inner probes. From this figure, it is seen that For GPD5 composite when current increased the sheet resistance rapidly decreased from 511.89 at $1 \mathrm{~mA}$ to 161.27 at $5 \mathrm{~mA}$. For GPD20 composite when current increased the sheet resistance slowly decreased from 36.24 at $1 \mathrm{~mA}$ to 20.11 at $5 \mathrm{~mA}$. It can be clearly observed that GPD5 composite has higher values of sheet resistances compared to GPD20 composite. So with increasing reduction time of GO in the composite the sheet resistance decreased and conductivity increased. 


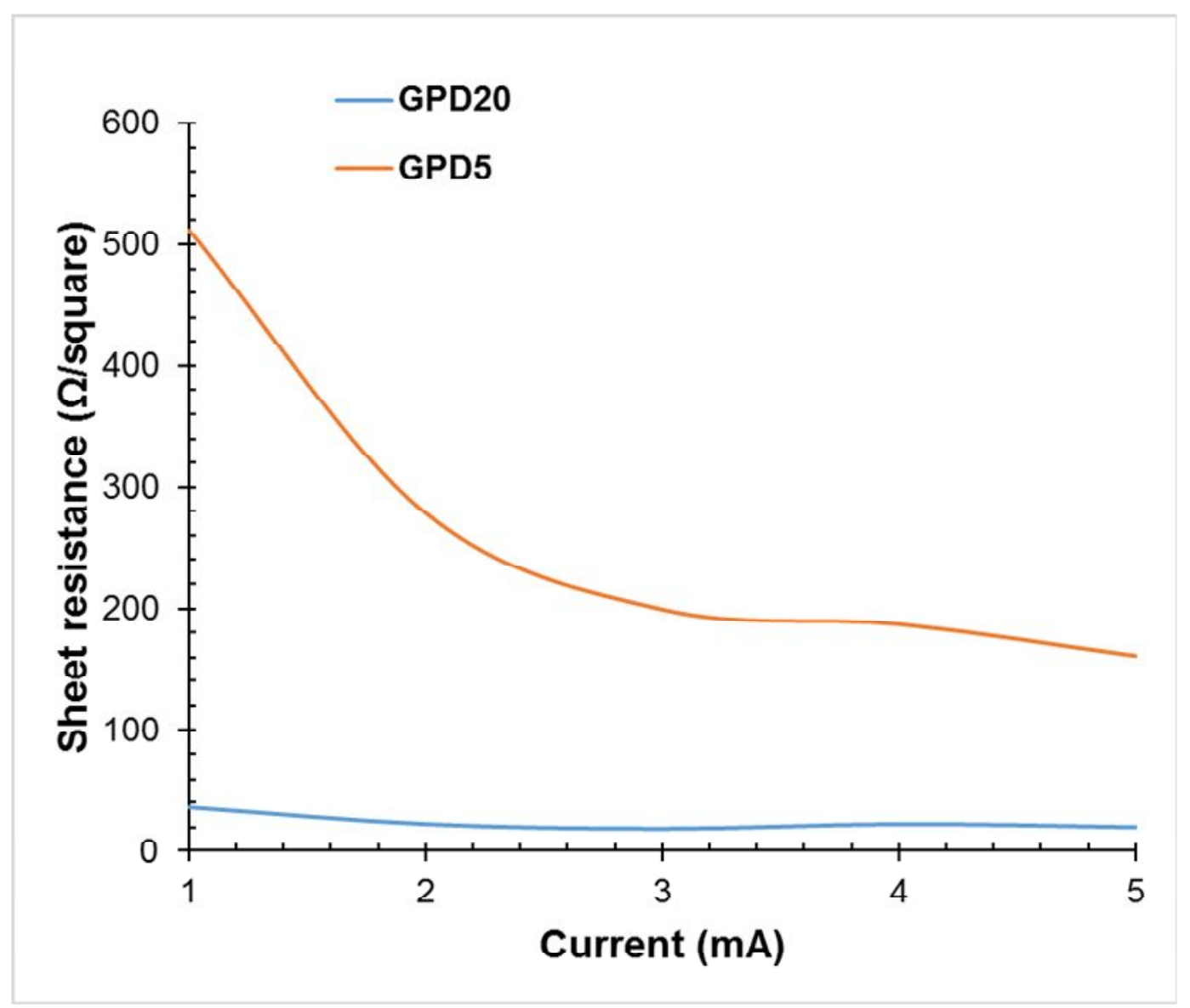

Figure (4): Sheet resistance curves of GPD5 and GPD20 composites

Figure (5) shows the CV of graphene/PANI supercapacitor of GPD20 composite using two probes connection at differe scan rates with scanning potential window is from -0.8 to $0.8 \mathrm{~V}$. The $\mathrm{CV}$ curve area is gradually enlarged with the increase of the scan rate. At low scan rate, there is sufficient time for electrolyte ions migration to the inner part of the electrode [12]. Oxidation and reduction peaks are appeared due to pseudocapacitance of PANI. The calculated specific capacitance was $1405.68 \mathrm{~F} / \mathrm{g}$ at scan rate of $1 \mathrm{mV} / \mathrm{s}$ and weight of active material was $4.9 \mathrm{mg}$. 


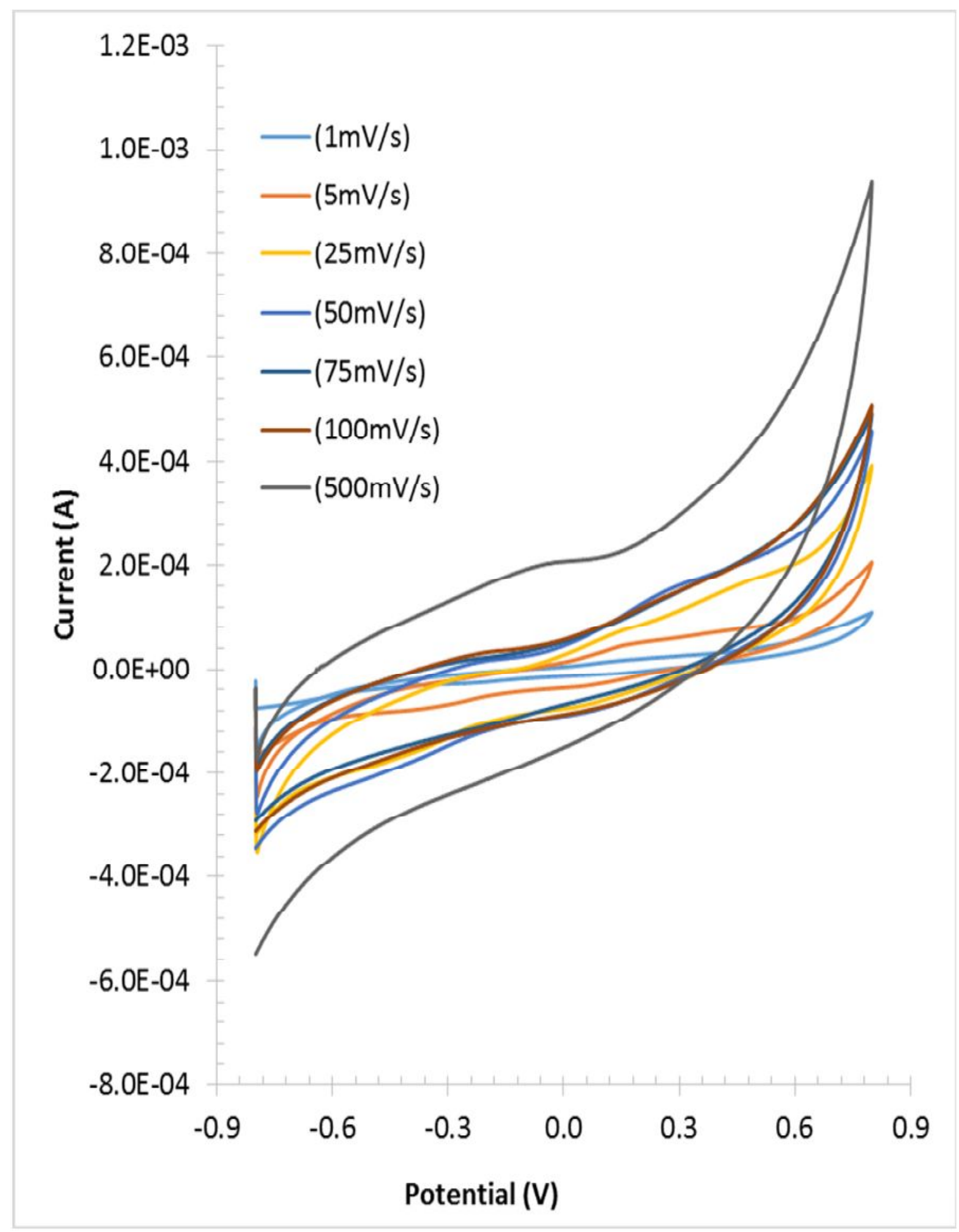

Figure (5): The CV curves of supercapacitor of GPD20 composite at different scan rates 
Figure (6) shows Nyquist plot of GPD20. It shows a semicircle in the high frequency region. The semicircle corresponds to charge transfer resistance (Rct). The intersection of the curve at the $\mathrm{x}$-axis represents the internal or equivalent series resistance (ESR). ESR is the sum of the electrolyte resistance, the intrinsic resistance of the active electrode material and the contact resistance at the interface of the active material and the current collector. The value of charge transfer resistance. From this Figure it is seen that the charge transfer resistance

( $\mathrm{R}_{\mathrm{ct}}$ ) was 39 and the equivalent series resistance (ESR) was 2.9. Also, the maximum of $\mathrm{Z}_{\text {imag }}(\max )$ was 21.3 .

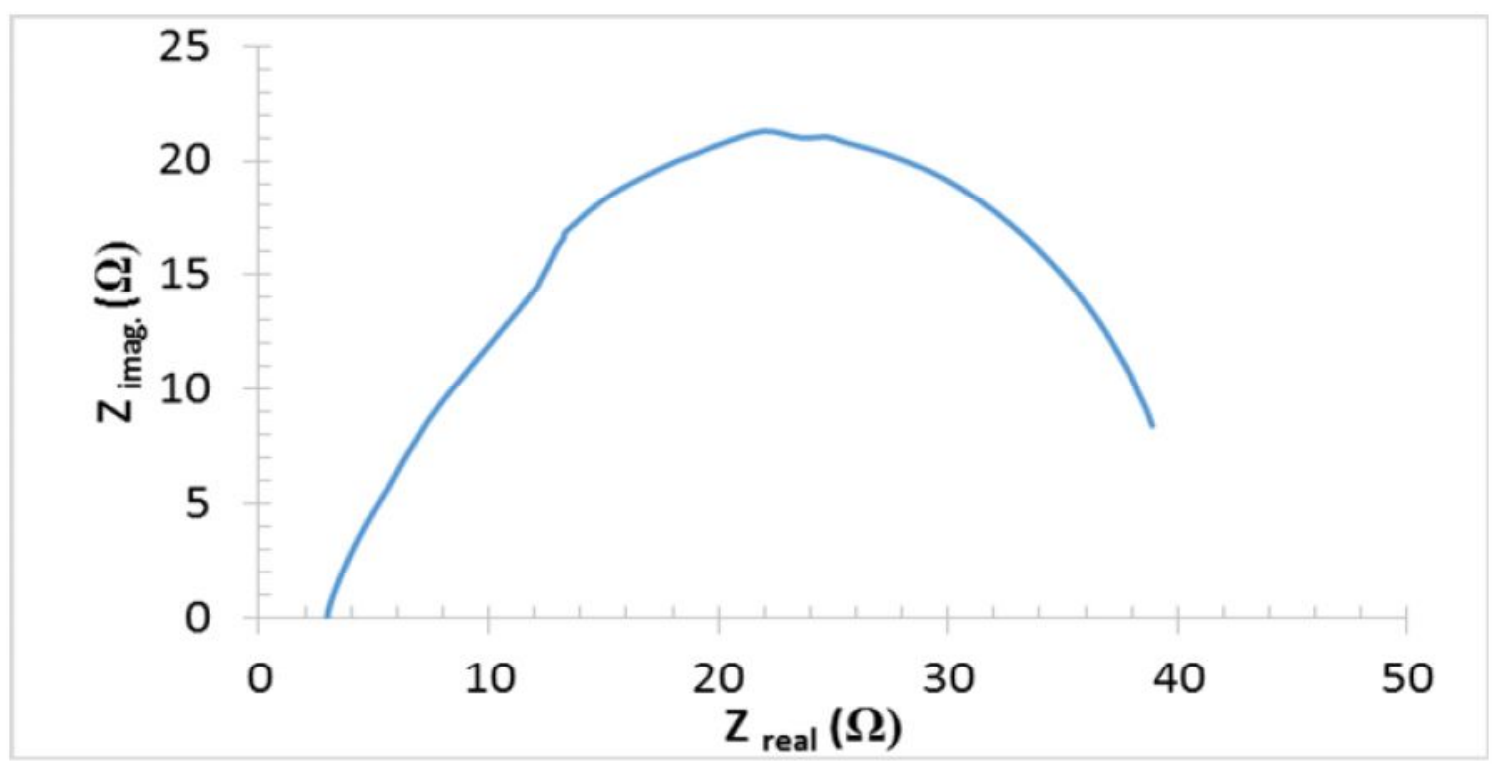

Figure (6): The Nyquist plot of GP20 supercapacitor

Figure (7) shows the galvanostatic of GP20 supercapacitor at constant specific current of $1 \mathrm{~A} / \mathrm{g}$ and $7 \mathrm{~A} / \mathrm{g}$. It exhibits semi triangular shape charge-discharge curves due to synergetic effect between graphene and PANI in the composite. The deviation from linearity is typically due to of pseudocapacitive contribution, which demonstrated that the capacitances of PANI mainly originate from pseudocapacitance plus electric double layer capacitance of graphene. The total charge-discharge time for GP20 supercapacitor is about $400 \mathrm{~s}$ at $7 \mathrm{~A} / \mathrm{g}$ and $2732 \mathrm{~s}$ at $1 \mathrm{~A} / \mathrm{g}$. 


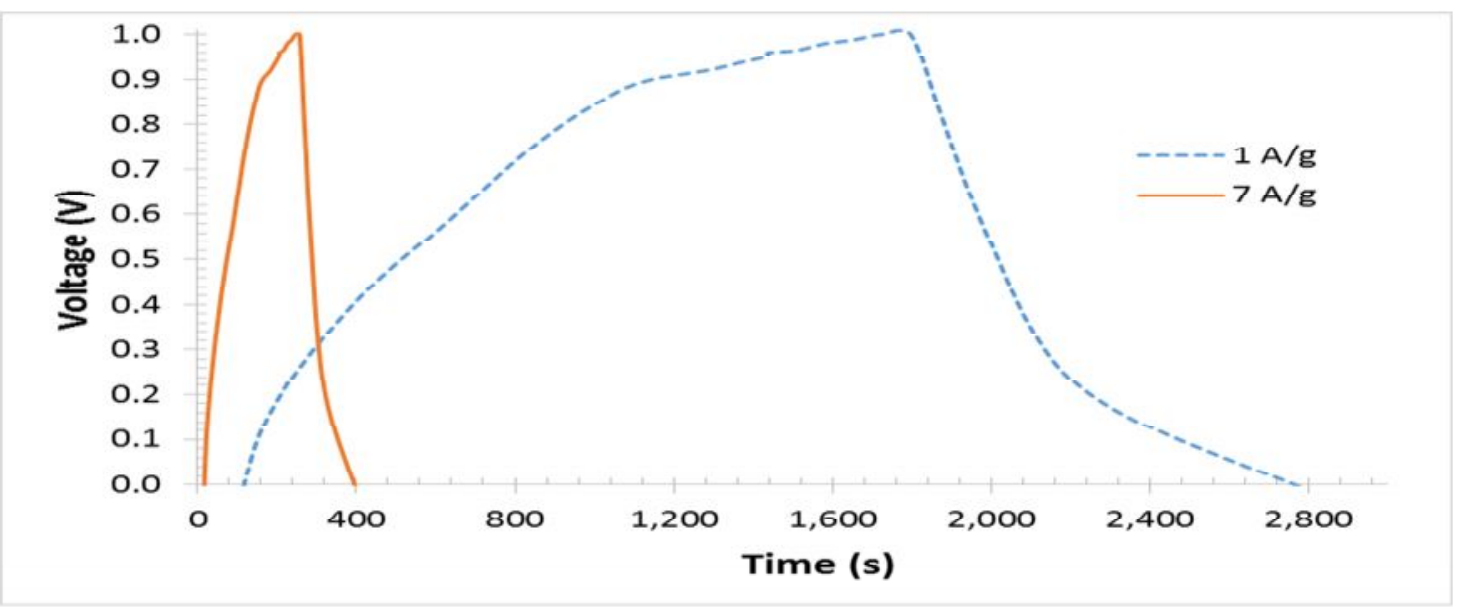

Figure (7): Charge-discharge curves of GP20 supercapacitor at constant current of 1 $A / g$ and $7 A / g$

\section{CONCLUSIONS}

Supercapacitors with graphene/PANI composite electrodes and filter paper separator were fabricated. GPD20 composite produced a specific capacitance of $1405.68 \mathrm{~F} / \mathrm{g}$ at scan rate of $1 \mathrm{mV} / \mathrm{s}$. The results show that with increasing reduction time, the oxygen content on the surface of GO was decreased, leading to increased ID/IG ratio in the Raman spectra of GO and increased conductivity of composite. With increasing reduction time of $\mathrm{GO}$ in the composite the sheet resistance decreased and conductivity increased. Consequently, the capacitance properties of GO/PANI composites were significantly improved by increasing reduction time from $5 \mathrm{~h}$ to 20 h.

\section{REFERENCES}

[1]H. Gómez, M.K. Ram, F. Alvi, P. Villalba, E. Stefanakos and A. Kumar, "Graphene conducting polymer nanocomposite as novel electrode for supercapacitors," J Power Sources, vol.196, pp.4102-4108, 2011.

[2]H. Nakanishi and B. A. Grzybowski, "Supercapacitors Based on Metal Electrodes Prepared from Nanoparticle Mixtures at Room Temperature", J. Phys. Chem. Lett., vol. 1, pp. 1428-1431, 2010.

[3] M. Jayalakshmi and K. Balasubramanian, "Energy storage in electrochemical capacitors: designing functional materials to improve performance," Int. J. Electrochem. Sci. , vol. 3, pp.1196, 2010.

[4] Y.Wang, H. Li and Y. Xia, "Ordered Whiskerlike Polyaniline grown on the surface of mesoporous marbon and its electrochemical capacitance performance," Adv. Mater., vol. 18, pp. 2619-2623, 2006.

[5] Y. Zhou, Z.Y. Qin, L. Li, Y. Zhang, Y.L. Wei, L.F. Wang and M.F. Zhu, "Polyaniline/multi-walled carbon nanotube composites with core shell structures as 
supercapacitor electrode materials," Electrochim. Acta, vol. 55, pp. 3904-3908, 2010.

[6] Y.T. Tan, F. Ran, L.B. Kong, J. Liu and L. Kang, "polyaniline nanoparticles grown on the surface of carbon microspheres aggregations for electrochemical supercapacitors," Synthetic Met., vol. 162, pp.114-118, 2012.

[7] J. Chen, B. Yao, C. Li and G. Shi, "An improved Hummers method for eco-friendly synthesis of graphene oxide," Carbon, vol. 64, pp. 225-229, 2013.

[8] Y. Sim, J. Park, Y.J. Kim and M.J. Seong, "Synthesis of graphene layers using graphite dispersion in aqueous surfactant solutions," J Korean Phys. Soc., vol. 58, pp. 938-942, 2011.

[9] Y. Hong, Z. Wang and X. Jin, "Sulfuric Acid intercalated graphite oxide for graphene preparation," Scientific Reports, vol. 3, pp. 1-6, 2013.

[10] S. Stankovich, D.A. Dikin, R.D. Piner, K.A. Kohlhaas, A. Kleinhammes, Y. Jia, Y. Wu, S.T. Nguyen and R.S. Ruoff, "Synthesis of graphene based nanosheets via chemical reduction of exfoliated graphite oxide," Carbon , vol. 45, pp. 1558-1565, 2007.

[11] F.P. Du, J.J. Wang, C.Y. Tang, C.P. Tsui, X.L. Xie and K.F. Yung, "Enhanced electrochemical capacitance of polyaniline/graphene hybrid nanosheets with graphene as templates," Compos. Part B-Eng., vol. 53, pp. 376-381, 2013.

[12] H. Wang, Q. Hao, X. Yang, L. Lu, X. Wang, A nanostructured graphene/polyaniline hybrid material for supercapacitors, Nanoscale 2(2010) 21642170.

[13] Z. Luo, L. Zhua, Y. Huang and H. Tang, "Effects of graphene reduction degree on capacitive performances of graphene/PANI composites," Synthetic Met., vol.175, pp. 88- 96, 2013.

[14] H. Gómez, M.K. Ram, F. Alvi, P. Villalba , E. Stefanakos and A. Kumar, "Graphene conducting polymer nanocomposite as novel electrode for supercapacitors," J Power Sources, vol. 196, pp. 4102-4108, 2011.

[15] J. Yang and L. Zou, "Graphene films of controllable thickness as binder free electrodes for high performance supercapacitors," Electrochim. Acta, vol.130, pp. 791-799, 2014.

[16] C. Bian and $\mathrm{A}$. Yu, "Dedoped polyaniline nanofibres with micropores for high rate aqueous electrochemical capacitor," Synthetic Met., vol. 160, pp. 1579-1583, 2010.

[17] B.C. Kim, J.S. Kwon, J.M. Ko, J.H. Park, C.O. Too and G.G. Wallace, "Preparation and enhanced stability of flexible supercapacitor prepared from Nafion/polyaniline nanofiber," Synthetic Met., vol. 160, pp. 94-98, 2010. 